Research Article

\title{
Comparison of In Vitro Antibacterial Activity of Epaltes divaricata and Vetiveria zizanioides against Methicillin- Resistant Staphylococcus aureus
}

\author{
Hasanga Rathnayake, ${ }^{1}$ Manikkuwadura Hasara Nethmini De Zoysa, ${ }^{2}$ \\ Ruwani Punyakanthi Hewawasam (D), \\ and Weerasinghe Mudiyanselage Dilip Gaya Bandara Wijayaratne $\mathbb{C}^{3}$ \\ ${ }^{1}$ Department of Biochemistry, Faculty of Medicine, University of Ruhuna, Matara, Sri Lanka \\ ${ }^{2}$ Department of Medical Laboratory Science, Faculty of Allied Health Sciences, University of Ruhuna, Matara, Sri Lanka \\ ${ }^{3}$ Department of Microbiology, Faculty of Medicine, University of Ruhuna, Matara, Sri Lanka
}

Correspondence should be addressed to Ruwani Punyakanthi Hewawasam; ruwaniph@yahoo.com

Received 29 May 2020; Accepted 25 June 2020; Published 14 July 2020

Academic Editor: Katsumi Doi

Copyright (c) 2020 Hasanga Rathnayake et al. This is an open access article distributed under the Creative Commons Attribution License, which permits unrestricted use, distribution, and reproduction in any medium, provided the original work is properly cited.

\begin{abstract}
Methicillin-resistant Staphylococcus aureus (MRSA) is a major cause of hospital- and community-acquired infections worldwide. Therefore, this study was conducted to explore the antibacterial activity of the two medicinal plants Epaltes divaricata and Vetiveria zizanioides against strains of MRSA which were isolated from patients with skin and soft tissue infections. Hexane, ethanol, and water extracts of E. divaricata (whole plant) and V. zizanioides (roots) were prepared. Clinical isolates of MRSA strains $(n=20)$ were used for the study. Bacterial susceptibility was tested using a disc diffusion assay. Minimum inhibitory concentration (MIC) was determined by a broth microdilution method. Vancomycin was used as the positive control. Hexane, ethanol, and water extracts of E. divaricata showed inhibitory zones against MRSA. Except for water extract, both hexane and ethanol extracts of $V$. zizanioides showed inhibitory zones. MIC ranges of hexane, ethanol, and water extracts in E. divaricata were $0.012-0.32 \mathrm{mg} / \mathrm{mL}, 0.019-2.4 \mathrm{mg} / \mathrm{mL}$, and $0.019-0.48 \mathrm{mg} / \mathrm{mL}$, respectively. Respective MIC ranges of hexane and ethanol extracts of $V$. zizanioides were $0.003-0.032 \mathrm{mg} / \mathrm{mL}$ and $0.019-2.4 \mathrm{mg} / \mathrm{mL}$. The hexane extract of $V$. zizanioides inhibited $55 \%$ of the selected MRSA strains at a relatively low MIC value of $0.012 \mathrm{mg} / \mathrm{mL}$. The hexane extract of both plants demonstrated inhibition of $75 \%$ of MRSA strains at a MIC value of $0.064 \mathrm{mg} / \mathrm{mL}$. Ethanol extract of V. zizanioides and E. divaricata, respectively, inhibited $70 \%$ and $45 \%$ of MRSA strains at the MIC of $0.096 \mathrm{mg} / \mathrm{mL}$, whereas water extract of E. divaricata inhibited $80 \%$ of MRSA strains at the same MIC. Both E. divaricata and V. zizanioides were equally effective against MRSA at a MIC of $0.064 \mathrm{mg} / \mathrm{mL}$. But $V$. zizanioides was more effective since the hexane extract inhibited more than 50\% of MRSA strains at significantly a lower MIC value of $0.012 \mathrm{mg} /$ $\mathrm{mL}$. Fractionation, purification, and identification of active compounds will warrant further evaluation of the therapeutic potential of both plant extracts.
\end{abstract}

\section{Introduction}

Antimicrobial resistance has become a major public health issue in the $21^{\text {st }}$ century which has threatened the prevention and the treatment of a wide variety of infections caused by bacteria, viruses, and fungi. The rate of emergence of antibiotic-resistant human pathogens is greater compared to the discovery of new antibiotic drugs [1]. Among the antibiotic-resistant organisms, methicillin-resistant Staphylococcus aureus (MRSA) causes a plethora of diseases involving the skin, soft tissue, bone, and joints [2]. It is one of the major causes of the hospital- and community-acquired infections [2]. The resistance for $\beta$-lactam antibiotics in MRSA is acquired by the expression of mecA gene [3]. Majority of clinical isolates of MRSA are also resistant to clindamycin, ciprofloxacin, and levofloxacin [4]. 
MRSA infections are prevalent in Sri Lanka mainly due to prophylactic and empiric use of antibiotics [5]. It is highly prevalent not only in hospitals but also in community samples in Sri Lanka [6]. Vancomycin is still the most commonly used antibiotic for multidrug-resistant $S$. aureus, but recent studies report the occurrence of $S$. aureus strains that are resistant to vancomycin in many countries including Sri Lanka [7]. Therefore, an urge of the discovery of new drugs to combat drug-resistant microorganisms including $S$. aureus is essential.

Medicinal plants are a key source of alternative medicine for fighting against diseases since ancient times. They are rich sources of valuable secondary metabolites which are capable of inhibiting microorganisms [8]. These natural products are also promising sources for the synthesis of novel antibacterial compounds. The whole plant of Epaltes divaricata and roots of Vetiveria zizanioides (Figure 1) are widely used in traditional medicine in Sri Lanka [9]. Vetiveria zizanioides ("Sevendara" in Sinhala) is commonly found in the warmer parts of the island. It is being used in Ayurveda for the treatment of typhoid fever, haemoptysis, phthisis, anaemia, skin and blood diseases, urinary disorders, piles, oedema, anorexia, chronic dyspepsia, flatulence, and acute and chronic congestion of the liver and jaundice [10]. Epaltes divaricata ("Heen-mudamahana" in Sinhala) is being used to treat skin diseases, oedema, pains, headaches, epilepsy, jaundice, haemorrhoids, hernia, and dysuria [11].

One of our previous studies reported the antibacterial activity of E. divaricata and $V$. zizanioides against standard organisms such as Staphylococcus aureus (ATCC 25923), Escherichia coli (ATCC 25922), Pseudomonas aeruginosa (ATCC 27853), and Klebsiella pneumoniae (ATCC 700603) [12]. However, in vitro studies on these plants for multidrugresistant organisms are not available. Therefore, this study explores the antibacterial activity against MRSA strains which were isolated from pus samples obtained for culture and sensitivity testing from patients having skin and soft tissue infections.

\section{Methods}

2.1. Plant Collection and Authentication. Whole plants of Epaltes divaricata and roots of Vetiveria zizanioides (Figure 1) were collected from the Southern Province in Sri Lanka. Authentication of the plants was confirmed at the National Herbarium, Botanical Gardens, Peradeniya, Sri Lanka. The plant material was thoroughly washed and dried in a hot air oven at $40^{\circ} \mathrm{C}$ for 3-4 days. Dried plant material was ground to a coarse powder and stored in sterile airtight containers at $4^{\circ} \mathrm{C}$.

\subsection{Preparation of Plant Extracts}

2.2.1. Ethanol and Hexane Extracts. $20 \mathrm{~g}$ of coarse powder of each plant material was mixed with $200 \mathrm{ml}$ of the solvent. The contents were placed in a mechanical shaker for $72 \mathrm{hr}$ at $25^{\circ} \mathrm{C}$. Then, the extracts were filtered, and the solvent was evaporated using a rotary evaporator. The resulting crude extracts were dissolved in a minimum amount of $10 \%$ dimethyl sulfoxide (DMSO) separately, and the final concentration of each extract was adjusted to $300 \mathrm{mg} / \mathrm{ml}$. Each extract was stored at $4^{\circ} \mathrm{C}$ in sterile airtight containers for further studies.

2.2.2. Water Extract. $2.62 \mathrm{~g}$ of dried plant material was refluxed in $60 \mathrm{ml}$ of distilled water for $3 \mathrm{hrs}$ to obtain the water extract. The resulting crude extract was dissolved in a minimum amount of $10 \%$ DMSO, and the final concentration of the extract was adjusted to $300 \mathrm{mg} / \mathrm{ml}$. The extract was stored at $4^{\circ} \mathrm{C}$ in sterile airtight containers for further studies.

2.3. Test Organisms. MRSA strains $(n=20)$ were used for the study along with CLSI (Clinical and Laboratory Standards Institute) standard strain of methicillin-sensitive S. aureus (MSSA-ATCC 25923) as the reference organism. The MRSA strains used in this study were isolated from pus samples obtained for culture and sensitivity testing from patients having skin and soft tissue infections among patients admitted to Teaching Hospital, Karapitiya, Sri Lanka. Organisms were subcultured for 24 hours on blood agar and MacConkey agar plates and confirmed by gram stain, catalase test, slide and tube coagulase tests, and the zone diameter of cefoxitin $(30 \mu \mathrm{g})$ on Mueller-Hinton agar at the Department of Microbiology, Faculty of Medicine, University of Ruhuna, Sri Lanka.

2.4. Bacterial Susceptibility Testing. Bacterial susceptibility was tested using the disc diffusion assay. Crude extract, 10-fold, and 100-fold dilutions of each plant extract were prepared in $10 \%$ DMSO. Bacteria cell suspensions were adjusted to $0.5 \mathrm{McF}$ arland turbidity standards to prepare $1 \times 10^{8} \mathrm{CFU} / \mathrm{ml}$ inoculum. Each standardized inoculum was introduced and evenly distributed on the surface of sterile Mueller-Hinton agar plates. Previously prepared sterile filter paper discs (Whatman No. 1, diameter $=6 \mathrm{~mm}$ ) were soaked in $10 \mu \mathrm{L}$ of each plant extract. They were placed on the seeded Mueller-Hinton agar plates. Vancomycin $(30 \mu \mathrm{g} /$ disc $)$ disk was used as the positive control, and 10\% DMSO-soaked filter paper disk was used as the negative control. The same procedure was used for all the MRSA strains used. The plates were incubated aerobically at $35 \pm 2^{\circ} \mathrm{C}$ for $18-24 \mathrm{hr}$. After incubation, diameters of the zones of inhibition were measured using a Vernier caliper. Each test was carried out in triplicate, and the average values of the diameters were considered. Activity index (AI) and relative percentage inhibition (RPI) for each extract were calculated using the following formula [13]:

$$
\begin{aligned}
\mathrm{RPI} & =\frac{100(X-Y)}{(Z-Y)}, \\
\mathrm{AI} & =\frac{\text { inhibition zone diameter of the sample }}{\text { inhibition zone of the standard }},
\end{aligned}
$$




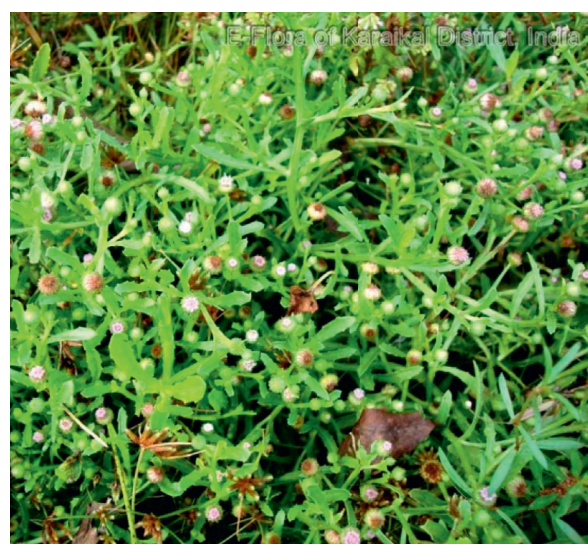

(a)

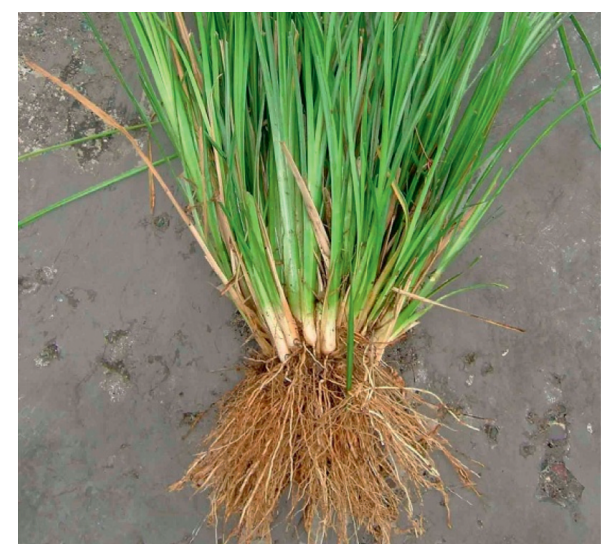

(b)

Figure 1: (a) Botanical name: Epaltes divaricata, local name: "Heen mudamahana," family: Compositae; (b) botanical name: Vetiveria zizanioides, local name: "Sevendara," family: Gramineae.

where $X=$ total area of inhibition of the test extract, $Y=$ total area of inhibition of the solvent, and $Z=$ total area of inhibition of the standard drug.

The total area of the inhibition was calculated by using area $=\pi r^{2}$; where $r=$ radius of zone of inhibition.

\subsection{Determination of Minimum Inhibitory Concentration} (MIC). Broth microdilution method was used to determine the MIC. Serial 5-fold dilutions of the plant extracts were prepared in the $10 \%$ DMSO, yielding serial dilutions of the crude extract. Bacterial inoculum was prepared in Mueller-Hinton broth, and the turbidity was adjusted to approximately $0.5 \mathrm{McFarland}$ turbidity standards. 96-well microtitre plates were used for the MIC assay, and $150 \mu \mathrm{L}$ of plant extract was added to each well of the microplate. $50 \mu \mathrm{L}$ of bacterial suspension was added to each well except the negative controls. Vancomycin ( $\mathrm{MIC} \leq 2 \mu \mathrm{g} / \mathrm{ml})$ was used as positive control. 10\% DMSO and plant extracts without bacterial suspension were used as the negative controls. Microtiter plates were incubated at $35 \pm 2{ }^{\circ} \mathrm{C}$ for $24 \mathrm{hr}$. Antimicrobial activity was assessed by the measurement of absorbance at $630 \mathrm{~nm}$ using a microplate reader. The lowest concentration (highest dilution) of the extract that does not produce bacterial growth depending on the absorbance was regarded as MIC. The assay was done in triplicate for each extract separately, and average absorbance values were used to determine the MIC.

2.6. Ethical Approval. Ethical approval was obtained from the Ethical Review Committee, Faculty of Medicine, University of Ruhuna, Sri Lanka.

2.7. Statistical Analysis. Mean standard error of means (SEM) was calculated to express data. The data were analysed using one-way ANOVA to compare the mean between groups. Mean differences at each point were considered significant at $p<0.05$.

\section{Results}

Disc diffusion assay was performed to detect the presence of inhibitory zones of $E$. divaricata and $V$. zizanioides against MRSA. Inhibitory zones were observed from crude extracts (hexane, ethanol, and water) of E. divaricata against MRSA (Figure 2 and Table 1). Except for water extract, both hexane and ethanol extracts of $V$. zizanioides showed inhibitory zones (Figure 3). Relatively larger inhibitory zones ranging from 13.1 to $18.7 \mathrm{~mm}$ were observed from the undiluted crude ethanol extract of E. divaricata, while diameters of inhibitory zones of water and hexane extracts were lower ranging from $6.6 \mathrm{~mm}$ to $15.6 \mathrm{~mm}$ and $6.7 \mathrm{~mm}$ to $13.1 \mathrm{~mm}$, respectively. Similarly, in $V$. zizanioides, larger inhibitory zones were observed from undiluted ethanol extract ranging from $6.4 \mathrm{~mm}$ to $13.3 \mathrm{~mm}$ followed by hexane extract which showed a diameter range of $6.5-11.4 \mathrm{~mm}$. Highest AI and RPI values were observed from crude ethanol extracts of both plants (Figure 4). Among diluted extracts of $E$. divaricata, inhibitory zones were observed from 10 -fold to 100 -fold diluted ethanol extracts. In $V$. zizanioides, only the 10-fold diluted ethanol extract showed inhibitory zones. Mean inhibitory zone of vancomycin $(30 \mu \mathrm{g} / \mathrm{disc})$ for MRSA and MSSA was $20.6 \mathrm{~mm}$ and $20.8 \mathrm{~mm}$, respectively. Compared to the MRSA strains, MSSA (ATCC 25923) also showed similar susceptibility pattern for the corresponding plant extracts (Table 1).

MIC ranges of hexane, ethanol, and water extracts in $E$. divaricata were $0.012-0.32 \mathrm{mg} / \mathrm{mL}, 0.019-2.4 \mathrm{mg} / \mathrm{mL}$, and $0.019-0.48 \mathrm{mg} / \mathrm{mL}$, respectively. Respective MIC ranges of hexane and ethanol extracts of $V$. zizanioides were $0.003-0.032 \mathrm{mg} / \mathrm{mL}$ and $0.019-2.4 \mathrm{mg} / \mathrm{mL}$. The hexane extract of $V$. zizanioides inhibited $75 \%$ of the selected MRSA strains at relatively low MIC values ranging from 0.003 to $0.064 \mathrm{mg} / \mathrm{mL}$. The hexane extract of E. divaricata inhibited $75 \%$ of MRSA strains at MIC values ranging from $0.012 \mathrm{mg} /$ $\mathrm{mL}$ to $0.064 \mathrm{mg} / \mathrm{mL}$. Ethanol extract of $V$. zizanioides inhibited $70 \%$ of MRSA strains at the MIC values ranging from $0.019 \mathrm{mg} / \mathrm{mL}$ to $0.096 \mathrm{mg} / \mathrm{mL}$, whereas ethanol and water extracts of E. divaricata, respectively, inhibited $45 \%$ 


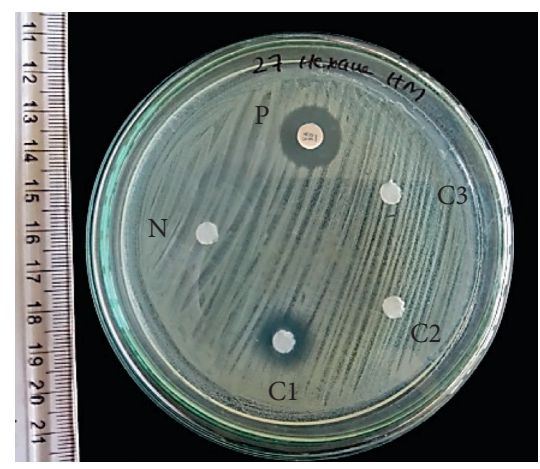

(a)

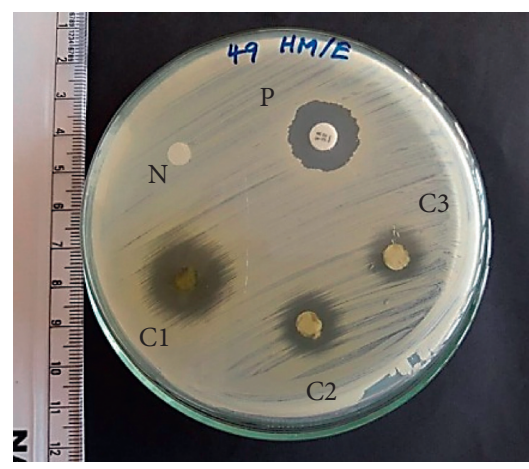

(b)

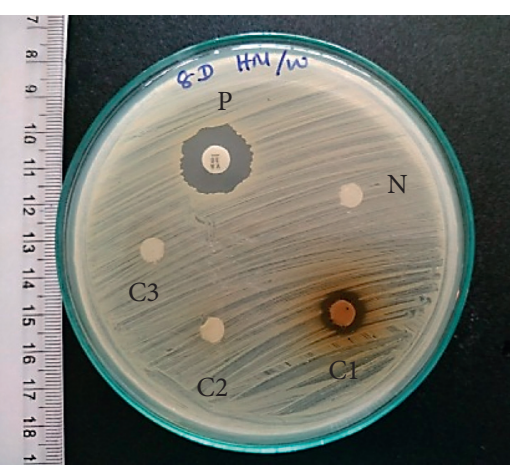

(c)

Figure 2: Inhibitory zones of crude extracts of E. divaricata: (a) hexane extract; (b) ethanol extract; (c) water extract. P: positive control; N: negative control; C1: crude extract; C2: 10-fold dilution of crude extract; C3: 100-fold dilution of crude extract.

TABLE 1: Diameter values of the disk diffusion assay of $E$. divaricata and V. zizanioides against MSSA and MRSA strains.

\begin{tabular}{|c|c|c|c|c|c|}
\hline \multirow{3}{*}{ Extract } & \multirow{3}{*}{ Concentration } & \multicolumn{4}{|c|}{ Inhibition zone diameter $(\mathrm{mm})$} \\
\hline & & \multicolumn{2}{|c|}{ MRSA } & \multicolumn{2}{|c|}{ MSSA (ATCC 25923) } \\
\hline & & E. divaricata & V. zizanioides & E. divaricata & V. zizanioides \\
\hline \multirow{3}{*}{ Hexane } & $40 \mathrm{mg} / \mathrm{mL}$ (crude) & $9.9(6.7-13.1)^{*}, n=20$ & $8.3(6.5-11.4), n=20$ & $13.7 \pm 0.1^{\#}$ & $11.4 \pm 0.2$ \\
\hline & $4 \mathrm{mg} / \mathrm{mL}$ (10x dilution) & - & - & - & - \\
\hline & $0.4 \mathrm{mg} / \mathrm{mL}$ (100x dilution) & - & - & - & - \\
\hline \multirow{3}{*}{ Ethanol } & 300 mg/mL (crude) & $15.4(13.1-18.7), n=20$ & $8.7(6.4-13.3), n=8$ & $16.3 \pm 0.2$ & $12.1 \pm 0.2$ \\
\hline & $30 \mathrm{mg} / \mathrm{mL}$ (10x dilution) & $10.1(7.4-11.7), n=18$ & $6.8(6.3-9.0), n=8$ & $13.4 \pm 0.2$ & $7.3 \pm 0.3$ \\
\hline & $3 \mathrm{mg} / \mathrm{mL}$ (100x dilution) & $7.1(6.3-10.1), n=8$ & - & $7.6 \pm 0.1$ & - \\
\hline \multirow{3}{*}{ Aqueous } & $150 \mathrm{mg} / \mathrm{mL}$ (crude) & $9.4(6.6-15.6), n=20$ & - & $7.4 \pm 0.2$ & - \\
\hline & 15 mg/mL (10x dilution) & - & - & - & - \\
\hline & $1.5 \mathrm{mg} / \mathrm{mL}$ (100x dilution) & - & - & - & - \\
\hline Vancomycin & $30 \mu \mathrm{g} /$ disc & \multicolumn{2}{|c|}{$20.6 \pm 2.2^{\dagger}$} & \multicolumn{2}{|c|}{$20.8 \pm 0.1^{\#}$} \\
\hline
\end{tabular}

$n$ denotes the number of isolates that showed a measurable diameter; ${ }^{*}$ data were expressed as mean (min-max); ${ }^{\#}$ data were expressed as mean \pm SEM; ${ }^{\dagger}$ mean \pm standard deviation.

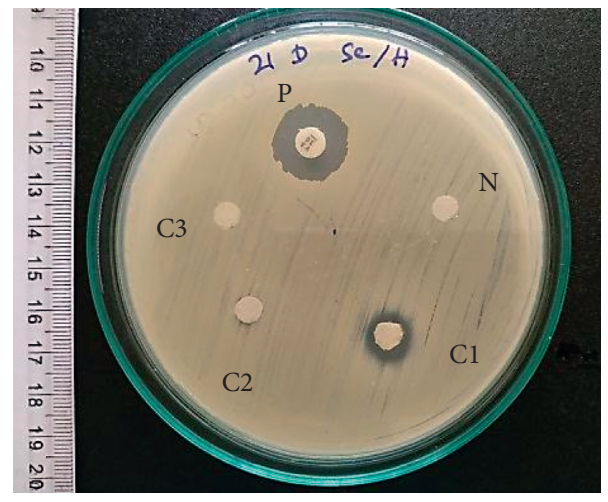

(a)

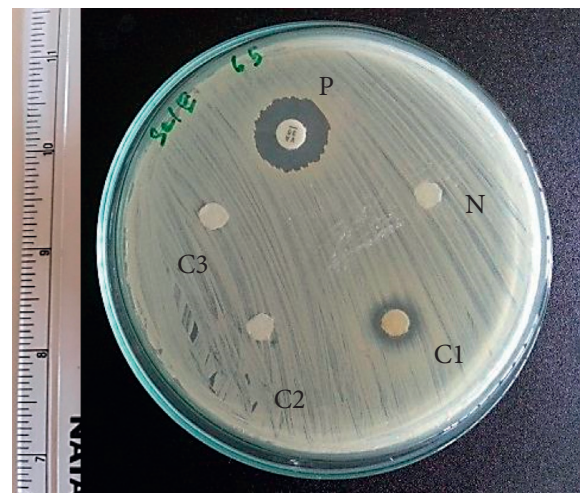

(b)

FIGURE 3: Inhibitory zones of crude extracts of V. zizanioides: (a) hexane extract; (b) ethanol extract. P: positive control; N: negative control; C1: crude extract; C2: 10-fold dilution of crude extract; C3: 100-fold dilution of crude extract.

and $80 \%$ of MRSA strains at the same MIC range. Relatively high MIC values of ethanol extracts of E. divaricata and $V$. zizanioides ranging from 0.48 to $2.4 \mathrm{mg} / \mathrm{mL}$ were needed to inhibit $55 \%$ and $30 \%$ of selected MRSA strains, respectively. Similarly, $0.48 \mathrm{mg} / \mathrm{mL}$ concentration of the water extract of
E. divaricata was needed to inhibit $20 \%$ of selected MRSA strains (Tables 2 and 3).

MRSA which were not effectively inhibited by extracts of E. divaricata was effectively inhibited by extracts of $V$. zizanioides, and vice versa. MRSA nos. 2 and 3 were 


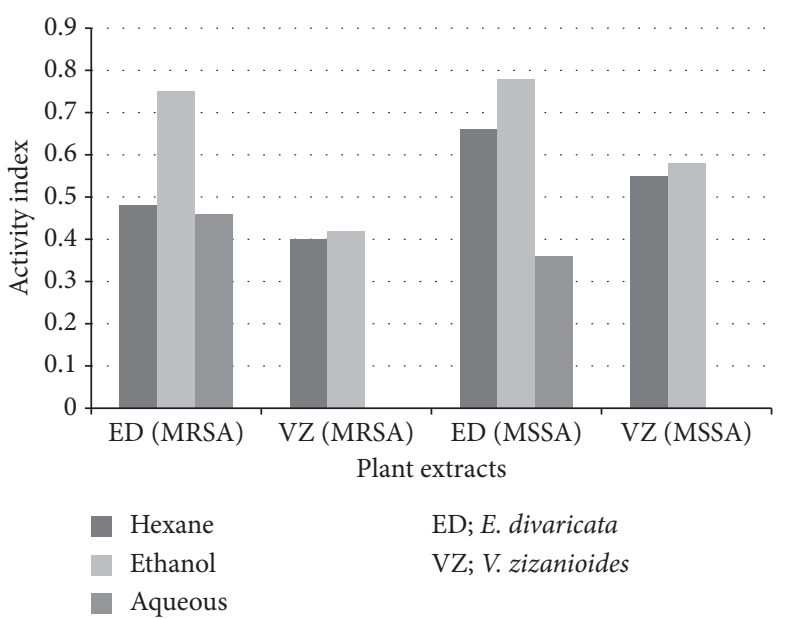

(a)

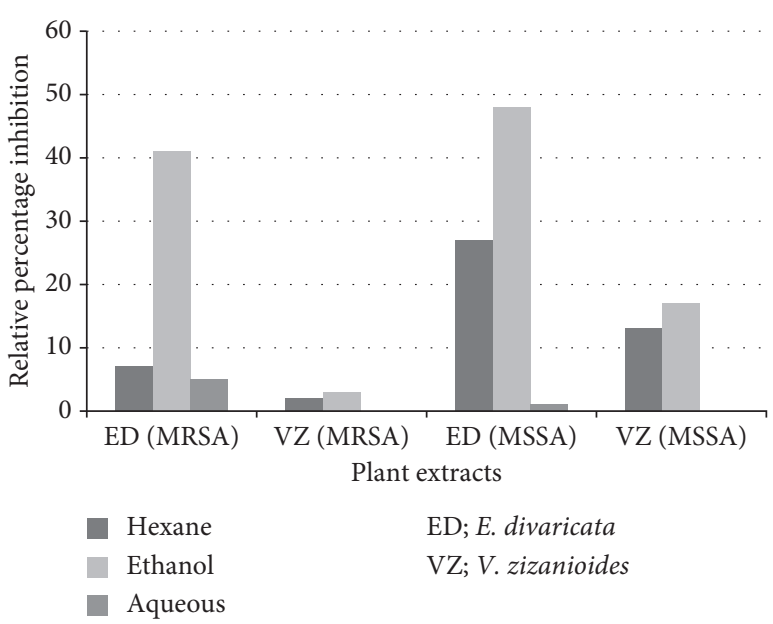

(b)

FIgURe 4: Activity index (a) and relative percentage inhibition (b) of crude extracts of E. divaricata and V. zizanioides for MRSA and MSSA.

TABLe 2: MIC values of E. divaricata and $V$. zizanioides against MRSA strains.

\begin{tabular}{|c|c|c|c|c|c|}
\hline \multirow{3}{*}{ MRSA strain } & \multicolumn{5}{|c|}{ Minimum inhibitory concentration $(\mathrm{mg} / \mathrm{mL})$} \\
\hline & \multicolumn{2}{|c|}{ Hexane extract } & \multicolumn{2}{|c|}{ Ethanol extract } & \multirow{2}{*}{$\begin{array}{l}\text { Water extract } \\
\text { E. divaricata }\end{array}$} \\
\hline & E. divaricata & V. zizanioides & E. divaricata & V. zizanioides & \\
\hline 1 & 0.064 & 0.064 & 0.09 & 0.48 & 0.09 \\
\hline 2 & 0.064 & 0.012 & 2.40 & 0.09 & 0.09 \\
\hline 3 & 0.32 & 0.012 & 2.40 & 0.09 & 0.48 \\
\hline 4 & 0.32 & 0.32 & 0.09 & 0.09 & 0.48 \\
\hline 5 & 0.32 & 0.012 & 0.48 & 0.09 & 0.09 \\
\hline 6 & 0.32 & 0.012 & 0.48 & 048 & 0.09 \\
\hline 7 & 0.064 & 0.003 & 0.09 & 0.09 & 0.09 \\
\hline 8 & 0.32 & 0.064 & 0.48 & 2.40 & 0.48 \\
\hline 9 & 0.012 & 0.32 & 0.48 & 2.40 & 0.48 \\
\hline 10 & 0.012 & 0.32 & 2.40 & 0.48 & 0.09 \\
\hline 11 & 0.064 & 0.012 & 0.48 & 0.09 & 0.09 \\
\hline 12 & 0.012 & 0.012 & 0.019 & 0.019 & 0.09 \\
\hline 13 & 0.064 & 0.003 & 0.09 & 0.09 & 0.09 \\
\hline 14 & 0.064 & 0.064 & 0.48 & 0.09 & 0.09 \\
\hline 15 & 0.064 & 0.012 & 0.09 & 0.019 & 0.09 \\
\hline 16 & 0.064 & 0.32 & 0.09 & 0.09 & 0.019 \\
\hline 17 & 0.064 & 0.012 & 0.09 & 0.019 & 0.09 \\
\hline 18 & 0.012 & 0.32 & 0.48 & 0.09 & 0.09 \\
\hline 19 & 0.012 & 0.064 & 0.48 & 0.09 & 0.019 \\
\hline 20 & 0.064 & 0.012 & 0.09 & 0.48 & 0.09 \\
\hline Mean (SEM) $n=20$ & $0.064^{*}(0.012-0.32)$ & $0.098^{*}(0.003-0.32)$ & $0.480 *(0.019-2.4)$ & $0.388 *(0.019-2.4)$ & $0.399^{*}(0.019-0.48)$ \\
\hline MSSA $^{\#}$ & 1.6 & 0.003 & 0.48 & 2.4 & 1.2 \\
\hline
\end{tabular}

${ }^{*}$ Data were expressed as mean (min-max); ${ }^{\#}$ methicillin-sensitive S. aureus (ATCC 25923).

inhibited at MIC of $2.4 \mathrm{mg} / \mathrm{mL}$ of the ethanol extract of $E$. divaricata, but they were inhibited at $0.012 \mathrm{mg} / \mathrm{mL}$ by the hexane extract of $V$. zizanioides. MRSA nos. 9 and 10 that were inhibited at MIC of $0.32 \mathrm{mg} / \mathrm{mL}$ of hexane extract of $V$. zizanioides were inhibited at $0.012 \mathrm{mg} / \mathrm{mL}$ by the hexane extract of E. divaricata. Furthermore, MIC values obtained for the different extracts of the same plant for individual MRSA also varied. MRSA no. 6 which was inhibited at MIC of $0.48 \mathrm{mg} / \mathrm{mL}$ of ethanol extract was also inhibited at MIC of $0.012 \mathrm{mg} / \mathrm{mL}$ of hexane extract of $V$. zizanioides. MRSA no. 9 was inhibited at MIC of
$2.4 \mathrm{mg} / \mathrm{mL}$ of ethanol extract, but it was also inhibited at MIC of $0.012 \mathrm{mg} / \mathrm{mL}$ of hexane extract of E. divaricata. The reference strain of S. aureus (ATCC 25923) was more sensitive for the hexane extract of $V$. zizanioides which required MIC of $0.003 \mathrm{mg} / \mathrm{mL}$. Relatively high MIC values ranging from 0.48 to $2.4 \mathrm{mg} / \mathrm{mL}$ of ethanol and hexane extracts were needed to inhibit $S$. aureus (ATCC 25923) (Table 2). There were no statistically significant differences in MIC between hexane, ethanol, and aqueous extracts of E. divaricata and $V$. zizanioides $(p>0.05)$. 
TABLe 3: Percentage of MRSA strains inhibited at different MIC values of E. divaricata and V. zizanioides.

\begin{tabular}{|c|c|c|c|c|c|}
\hline \multirow{3}{*}{$\mathrm{MIC}(\mathrm{mg} / \mathrm{mL})$} & \multicolumn{5}{|c|}{ Percentage (\%) of MRSA inhibited } \\
\hline & \multicolumn{2}{|c|}{ Hexane extract } & \multicolumn{2}{|c|}{ Ethanol extract } & \multirow{2}{*}{$\begin{array}{l}\text { Water extract } \\
\text { E. divaricata }\end{array}$} \\
\hline & E. divaricata & V. zizanioides & E. divaricata & V. zizanioides & \\
\hline 0.003 & - & $10 \%(n=2)$ & - & - & - \\
\hline 0.012 & $25 \%(n=5)$ & $45 \%(n=9)$ & - & - & - \\
\hline 0.019 & - & - & $5 \%(n=1)$ & $15 \%(n=3)$ & $10 \%(n=2)$ \\
\hline 0.064 & $50 \%(n=10)$ & $20 \%(n=4)$ & - & - & - \\
\hline 0.096 & - & - & $40 \%(n=8)$ & $55 \%(n=11)$ & $70 \%(n=14)$ \\
\hline 0.320 & $25 \%(n=5)$ & $25 \%(n=5)$ & - & - & - \\
\hline 0.480 & - & - & $40 \%(n=8)$ & $20 \%(n=4)$ & $20 \%(n=4)$ \\
\hline 2.400 & - & - & $15 \%(n=3)$ & $10 \%(n=2)$ & - \\
\hline Total & $100 \%(n=20)$ & $100 \%(n=20)$ & $100 \%(n=20)$ & $100 \%(n=20)$ & $100 \%(n=20)$ \\
\hline
\end{tabular}

$n=$ number of MRSA strains.

\section{Discussion}

The results revealed that the crude extracts of E. divaricata and $V$. zizanioides were effective against the MRSA strains as observed by the zones of inhibition. Disc diffusion assay was performed as a preliminary screening to confirm the inhibitory effects of the plant extracts against MRSA. Highest $\mathrm{AI}$ and RPI values were obtained from crude ethanol extracts of the plants. Since undiluted crude extracts were more effective against MRSA, it is assumed that the antibacterial effect may be due to the presence of possible active ingredients in high concentrations. However, the strength of an inhibitory effect cannot be compared by the results of disc diffusion assay due to the varying concentrations of the crude extracts. Therefore, MIC was determined as the standard method to compare the antibacterial activity of the plant extracts.

The MIC values obtained for the extracts against the MRSA varied from one plant extract to another. One reason would be the extraction of different constituents in particular solvents depending on their chemical and physical properties especially the polarity. Furthermore, due to genetic variability, different MRSA could have acted differently with chemicals in each extract. Organisms which were not effectively inhibited by $E$. divaricata were effectively inhibited by extract of $V$. zizanioides, and vice versa, suggesting the effectiveness of both plants towards different strains of MRSA. However, V. zizanioides is more effective since hexane extracts inhibited majority of MRSA strains at relatively lower MIC such as $0.003 \mathrm{mg} / \mathrm{mL}$. Low polar active compounds present in the hexane extract may be responsible for this antimicrobial activity. As observed in our previous studies, compared to the MRSA strains, S. aureus ATCC standard (ATCC 25923) also showed similar susceptibility pattern for both plants [12]. This could be due to the genetic similarities between MSSA (ATCC 25923) and MRSA.

Studies conducted in Sri Lanka revealed that certain medicinal plants which are being used in traditional medicine possess anti-MRSA properties [14, 15]. However, local studies on E. divaricata and $V$. zizanioides, related to MRSA, were deficient. On the contrary, very few studies were available from other countries on these plants which reported anti-MRSA activity. Glorybai et al. reported the presence of antibacterial activities of E. divaricata in 2015, but they have used a single strain of MRSA, and MIC was not reported [16]. Furthermore, their study revealed the presence of phenolic compounds, 2butenamide, $\mathrm{N}$-(4-fluorophenyl)-methyl trans-cinnamyl tiglate silane, trichlorocyclohexyl silane, and its derivatives in $E$. divaricata, which could be responsible for the antibacterial activity. Sivagurunathan and Krishnamoorthy reported the antibacterial properties of $V$. zizanioides for a single strain of MRSA in 2017, but MIC was not reported. High concentrations of phenolic compounds were identified in the ethanol extract, and HPLC results showed the presence of different types of unidentified phytoconstituents [17]. Zuo et al. reported anti-MRSA activity of 19 medicinal plants against 9 MRSA strains (except $E$. divaricata and $V$. zizanioides) with MIC range of $1.25-3.07 \mathrm{mg} / \mathrm{ml}[18]$.

There were many reports in the recent past on the antimicrobial activity of medicinal plants against many microorganisms including MRSA. Dahiya and Purkayastha reported antibacterial activity of seven medicinal plants for a single strain of MRSA in 2012 [19]. Extracts of Tulsi, oregano, rosemary, and Aloe vera were included in their study, and MIC values were found to be in the range of $1.56-6.25 \mathrm{mg} / \mathrm{ml}$. When compared to other studies conducted by Okwu et al., Zuo et al., and Dahiya and Purkayastha [18-20], extracts of E. divaricata and V. zizanioides in the present study exhibited relatively lower MICs against MRSA.

Trong Le et al. reported antimicrobial activities of essential oils extracted from Paramignya trimera and Limnocitrus littoralis which were used in the Vietnamese traditional medicine [21]. P. trimera strongly inhibited $S$. aureus ATCC 43300 and the $S$. aureus clinical strain with MIC and MLC (minimum lethal concentration) values of $2 \%$ $(\mathrm{v} / \mathrm{v})$, but $L$. littoralis did not inhibit $S$. aureus. Oil extracted from $P$. trimera consisted of $\beta$-caryophyllene, $\beta$-caryophyllene oxide, 7 -epi- $\alpha$-eudesmol, and $\gamma$-muurolene as major components. This suggested that the presence of $\beta$-caryophyllene and $\beta$-caryophyllene oxide may be responsible for the antibacterial activity of $P$. trimera against $S$. aureus. Another Vietnamese study on essential oil extracted from the leaves of Leoheo domatiophorus inhibited S. aureus ATCC 43300 and the S. aureus clinical strain [22]. Both $S$. aureus strains were inhibited at MIC of $0.25 \%(\mathrm{v} / \mathrm{v})$ and 
MLC of $0.5 \%(\mathrm{v} / \mathrm{v})$. GC/MS (gas chromatography/mass spectrometry) analysis of the essential oil of L. domatiophorus indicated the presence of sesquiterpene hydrocarbons, oxygenated sesquiterpenes as the main classes of compounds. Viridiflorene, $(-)-\delta$-cadinene, and $\gamma$-muurolene were present at higher concentrations, while $\alpha$-muurolene, $\gamma$-cadinene, $(+)$-aromadendrene, $\alpha$-cadinol, and globulol were present at lower concentrations.

Many other studies published recently also reported the presence of compounds of natural origin that could alleviate the symptoms associated with skin infections. A study conducted on water extract of Borojoa patinoi which was used in Colombian traditional medicine did not inhibit $S$. aureus M121 which is resistant to both methicillin and vancomycin [23]. However, the extract inhibited multidrugresistant (MDR) Pseudomonas aeruginosa and the UHPLC (ultrahigh performance liquid chromatography) analysis of the plant extract showed the presence of 26 phenolic compounds including hydroxycinnamic acids, phenolic acids, flavonols, flavan-3-ols, flavonones, flanones, tyrosol ester, and dihydrochalcones. Mazzarello et al. reported that a skin cream containing propolis $20 \%$, tea tree oil $3 \%$, and Aloe vera $10 \%$ was effective in reducing acne [24]. Pathogenesis of acne is associated with Propionibacterium acnes, S. aureus, and S. epidermidis. Propolis consists of flavonoids, caffeic acid, benzoic acid, and cinnamic acid. Tea tree oil contains terpinen-4-ol, which shows an important role in the antimicrobial activity. Besides, another study on acne reported antiacne efficacy of two essential oils extracted from Origanum vulgare and Myrtus communis L. [25]. Presence of monoterpene, diterpene, sesquiterpene hydrocarbons, azulene, alcohols, aldehydes, and ketones in essential oils may have attributed to the antibacterial effects against MDR bacteria [26].

One of our previous studies also confirmed the presence of tannins, phenolic compounds, cardiac glycosides, flavonoids, alkaloids, and saponins in both $E$. divaricata and $V$. zizanioides plant extracts [12]. Dos Santos et al. reported that $\beta$-vetivenene, khusimol, vetiselinenol, isovalencenol, vetivenic acid, $\alpha$-vetivone, and $\beta$-vetivone are the major constituents of dichloromethane fraction of Vetiveria zizanioides [27]. Antimicrobial activity of plant phenolics including flavonoids has also been documented in the past [28]. As evident from the abovementioned studies, active compounds isolated from medicinal plants have a significant potential to alleviate the symptoms associated with skin infections. Composition of active compounds in these plants could vary from one country to another due to different geographical and environmental conditions. Antimicrobial activities could be enhanced if the active compounds of the species under study that were collected from Sri Lanka are purified [29]. Therefore, further investigations which involve fractionation, purification, and identification of active compounds are necessary to develop these two plants as potential therapeutic agents in the future. Previous studies conducted in our laboratory reported the absence of any toxicological effects (biochemical, haematological, and histopathological) in ICR mice when treated with water extracts of E. divaricata and $V$. zizanioides [9]. However, toxicological studies on hexane and ethanol extracts have not been conducted yet. To develop potential therapeutics with anti-MRSA properties from these plant extracts, the toxicity of active compounds and their pharmacokinetics should be investigated. In vivo studies including clinical trials are necessary to confirm the efficacy of active compounds.

\section{Conclusion and Recommendation}

Here, we present preliminary findings of antibacterial activities of crude extracts of $E$. divaricata and $V$. zizanioides against twenty clinical isolates of MRSA. Both plants are equally effective against MRSA at a MIC of $0.064 \mathrm{mg} / \mathrm{mL}$, but $V$. zizanioides is more effective since the hexane extract inhibited more than $50 \%$ of MRSA strains at significantly lower MIC of $0.012 \mathrm{mg} / \mathrm{mL}$. Presence of phenolic compounds, alkaloids, and flavonoids identified in a previous study confirmed the presence of possible active compounds responsible for the antimicrobial effect in both $E$. divaricata and $V$. zizanioides. Since hexane extract was proven as the most active extract, low polar active phytochemicals present in the plant extracts may be responsible for this antimicrobial activity. Fractionation, purification, and identification of active compounds are essential in developing these extracts as potential therapeutics. In vivo studies will be performed with purified active components to investigate their pharmacokinetics and toxic effects in the future.

\section{Data Availability}

The data used to support the findings of the present study are available from the corresponding author upon request.

\section{Conflicts of Interest}

The authors declare that they have no conflicts of interest.

\section{Authors' Contributions}

Hasanga Rathnayake and Manikkuwadura Hasara Nethmini De Zoysa contributed equally to this work.

\section{Acknowledgments}

This study was funded by the Faculty Research Grant of the Faculty of Medicine, University of Ruhuna, Sri Lanka. The authors are grateful to the technical officers and other nonacademic staff members at the Departments of Biochemistry, Microbiology, and Nuclear Medicine Unit, Faculty of Medicine, University of Ruhuna, Sri Lanka, for their technical and other assistance to make the present study a success.

\section{References}

[1] S. B. Zaman, M. A. Hussain, R. Nye, V. Mehta, K. T. Mamun, and N. Hossain, "A review on antibiotic resistance: alarm bells are ringing," Cureus, vol. 9, no. 6, Article ID e1403, 2017.

[2] A. Hassoun, P. K. Linden, and B. Friedman, "Incidence, prevalence, and management of MRSA bacteremia across 
patient populations-a review of recent developments in MRSA management and treatment," Critical Care (London, England), vol. 21, no. 1, p. 211, 2017.

[3] J. Rolo, P. Worning, J. Boye Nielsen, and R. Sobral, "Evidence for the evolutionary steps leading to mecA-mediated betalactam resistance in staphylococci," PLoS Genetics, vol. 13, Article ID e1006674, 2017.

[4] A. C. Gales, H. S. Sader, J. Ribeiro, C. Zoccoli, A. Barth, and A. C. Pignatari, "Antimicrobial susceptibility of gram-positive bacteria isolated in Brazilian hospitals participating in the SENTRY program (2005-2008)," Brazilian Journal of Infectious Diseases, vol. 13, no. 2, pp. 90-98, 2009.

[5] E. Corea, T. de Silva, and J. Perera, "Methicillin-resistant Staphylococcus aureus: prevalence, incidence and risk factors associated with colonization in Sri Lanka," Journal of Hospital Infection, vol. 55, no. 2, pp. 145-148, 2003.

[6] W. Samaranayake, L. Karunanayake, and C. Patabendige, "Characteristics of community acquired and hospital acquired methicillin resistant Staphylococcus aureus isolates in the national hospital of Sri Lanka," Sri Lankan Journal of Infectious Diseases, vol. 9, no. 1, pp. 24-31, 2019.

[7] D. R. Chung, C. Lee, Y. R. Kang et al., "Genotype-specific prevalence of heterogeneous vancomycin-intermediate Staphylococcus aureus in Asian countries," International Journal of Antimicrobial Agents, vol. 46, no. 3, pp. 338-341, 2015.

[8] R. Subramani, M. Narayanasamy, and K. D. Feussner, "Plantderived antimicrobials to fight against multi-drug-resistant human pathogens," 3 Biotech, vol. 7, p. 172, 2017.

[9] R. P. Hewawasam, K. A. P. W. Jayatilaka, L. K. B. Mudduwa, and C. Pathirana, "Toxicological evaluation of five Sri Lankan medicinal plants: a biochemical, haematological and histopathological assessment," International Journal of Pharmaceutical Sciences and Research, vol. 7, no. 10, pp. 4014-4021, 2016.

[10] D. M. A. Jayaweera, Medicinal Plants (Indigenous and Exotic) used in Ceylon, Part III, National Science Council, Colombo, Sri Lanka, 1982.

[11] M. D. Dassanayake and F. R. Fosberg, A Revised Handbook to the Flora of Ceylon, Vol. 1-14, Amerind Publishers, New Delhi, India, 1980.

[12] M. H. N. De Zoysa, H. Rathnayake, R. P. Hewawasam, and W. M. D. G. B. Wijayaratne, "Determination of in vitro antimicrobial activity of five Sri Lankan medicinal plants against selected human pathogenic bacteria," International Journal of Microbiology, vol. 2019, Article ID 7431439, 8 pages, 2019.

[13] D. Dharajiya, P. Patel, M. Patel, and N. Moitra, "In vitro antimicrobial activity and qualitative phytochemical analysis of Withania somnifera (L.) dunal extracts," International Journal of Pharmaceutical Sciences Review and Research, vol. 27, no. 60, pp. 349-354, 2014.

[14] T. Gunasekara, N. Radhika, K. Ragunathan et al., "Determination of antimicrobial potential of five herbs used in ayurveda practices against Candida albicans, Candida parapsilosis and methicillin resistant Staphylococcus aureus," Ancient Science of Life, vol. 36, no. 4, pp. 187-190, 2017.

[15] M. P. J. Dharmaratne, A. Manoraj, V. Thevanesam et al., "Terminalia bellirica fruit extracts: in-vitro antibacterial activity against selected multidrug-resistant bacteria, radical scavenging activity and cytotoxicity study on BHK-21 cells," BMC Complementary and Alternative, vol. 18, no. 1, p. 325, 2018.
[16] L. Glorybai, K. B. Kannan, M. V. Arasu, N. A. Al-Dhabi, and P. Agastian, "Some biological activities of Epaltes divaricata L.- - an in vitro study," Annals of Clinical Microbiology and Antimicrobials, vol. 14, p. 18, 2015.

[17] S. K. Sivagurunathan and G. Krishnamoorthy, "Comparative study on high-performance thin layer chromatography profile and antimicrobial activity of ethanolic and hydroalcoholic extract of Vetiveria zizanioides L. root," Asian Journal of Pharmaceutical and Clinical Research, vol. 10, no. 6, pp. 336-339, 2017.

[18] G. Y. Zuo, G. C. Wang, Y. B. Zhao et al., "Screening of Chinese medicinal plants for inhibition against clinical isolates of methicillin-resistant Staphylococcus aureus (MRSA)," Journal of Ethnopharmacology, vol. 120, no. 2, pp. 287-290, 2008.

[19] P. Dahiya and S. Purkayastha, "Phytochemical screening and antimicrobial activity of some medicinal plants against multidrug resistant bacteria from clinical isolates," Indian Journal of Pharmaceutical Sciences, vol. 74, no. 5, pp. 443-450, 2012.

[20] M. U. Okwu, M. Olley, A. O. Akpoka, and O. E. Izevbuwa, "Methicillin-resistant Staphylococcus aureus (MRSA) and anti-MRSA activities of extracts of some medicinal plants: a brief review," AIMS Microbiology, vol. 5, no. 2, pp. 117-137, 2019.

[21] N. Trong Le, D. Viet Ho, T. Quoc Doan et al., "Biological activities of essential oils from leaves of Paramignya trimera (oliv.) Guillaum and Limnocitrus littoralis (Miq.) Swingle," Antibiotics, vol. 9, no. 4, p. 207, 2020.

[22] N. Trong Le, D. Viet Ho, T. Quoc Doan et al., "In vitro antimicrobial activity of essential oil extracted from leaves of Leoheo domatiophorus Chaowasku, D. T. Ngo and H. T. Le in Vietnam," Plants (Basel, Switzerland), vol. 9, no. 4, p. 453, 2020.

[23] C. Chaves-López, D. Usai, M. G. Donadu et al., "Potential of Borojoa patinoi Cuatrecasas water extract to inhibit nosocomial antibiotic resistant bacteria and cancer cell proliferation in vitro," Food \& Function, vol. 9, no. 5, pp. 2725-2734, 2018.

[24] V. Mazzarello, M. Donadu, M. Ferrari et al., "Treatment of acne with a combination of propolis, tea tree oil, and Aloe vera compared to erythromycin cream: two double-blind investigations," Clinical Pharmacology: Advances and Applications, vol. 10, pp. 175-181, 2018.

[25] V. Mazzarello, E. Gavini, M. G. Donadu et al., "Clinical assessment of new topical cream containing two essential oils combined with tretinoin in the treatment of acne," Clinical, Cosmetic and Investigational Dermatology, vol. 13, pp. 233239, 2020.

[26] S. Cannas, D. Usai, A. Pinna et al., "Essential oils in ocular pathology: an experimental study," The Journal of Infection in Developing Countries, vol. 9, no. 6, pp. 650-654, 2015.

[27] D. S. Dos Santos, J. V. Oberger, R. Niero et al., "Seasonal phytochemical study and antimicrobial potential of Vetiveria zizanioides roots," Acta Pharmaceutica, vol. 64, no. 4, pp. 495-501, 2014.

[28] T. Hatano, H. Uebayashi, H. Ito, S. Shiota, T. Tsuchiya, and T. Yoshida, "Phenolic constituents of Cassia seeds and antibacterial effect of some naphthalenes and anthraquinones on methicillin-resistant Staphylococcus aureus," Chemical \& Pharmaceutical Bulletin, vol. 47, no. 8, pp. 1121-1127, 1999.

[29] D. C. M. Costa, M. M. B Azevedo, D. O. E. Silva et al., "In vitro anti-MRSA activity of Couroupita guianensis extract and its component Tryptanthrin," Natural Product Research, vol. 31, no. 17, pp. 2077-2080, 2017. 